\title{
The Role of Snapin in Neurosecretion: Snapin Knock-Out Mice Exhibit Impaired Calcium-Dependent Exocytosis of Large Dense-Core Vesicles in Chromaffin Cells
}

\author{
Jin-Hua Tian, ${ }^{1 *}$ Zheng-Xing Wu, ${ }^{2 *}$ Michael Unzicker, ${ }^{2}$ Li Lu, ${ }^{1}$ Qian Cai, ${ }^{1}$ Cuiling Li, $^{3}$ Claudia Schirra, ${ }^{2}$ Ulf Matti, ${ }^{2}$ \\ David Stevens, ${ }^{2}$ Chuxia Deng, ${ }^{3}$ Jens Rettig, ${ }^{2}$ and Zu-Hang Sheng ${ }^{1}$ \\ ${ }^{1}$ Synaptic Function Unit, National Institute of Neurological Disorders and Stroke, National Institutes of Health, Bethesda, Maryland 20892-3701, \\ ${ }^{2}$ Physiologisches Institut, Universitaet des Saarlandes, 66424 Homburg/Saar, Germany, and ${ }^{3}$ Mammalian Genetics Section, Genetics of Development and \\ Disease Branch, National Institute of Diabetes and Digestive and Kidney Diseases, National Institutes of Health, Bethesda, Maryland 20892
}

Identification of the molecules that regulate the priming of synaptic vesicles for fusion and the structural coupling of the calcium sensor with the soluble $\mathrm{N}$-ethyl maleimide sensitive factor adaptor protein receptor (SNARE)-based fusion machinery is critical for understanding the mechanisms underlying calcium-dependent neurosecretion. Snapin binds to synaptosomal-associated protein $25 \mathrm{kDa}$ (SNAP-25) and enhances the association of the SNARE complex with synaptotagmin. In the present study, we abolished snapin expression in mice and functionally evaluated the role of Snapin in neuroexocytosis. We found that the association of synaptotagmin-1 with SNAP-25 in brain homogenates of snapin mutant mice is impaired. Consequently, the absence of Snapin in embryonic chromaffin cells leads to a significant reduction of calcium-dependent exocytosis resulting from a decreased number of vesicles in releasable pools. 0verexpression of Snapin fully rescued this inhibitory effect in the mutant cells. Furthermore, Snapin is relatively enriched in the purified large densecore vesicles of chromaffin cells and associated with synaptotagmin-1. Thus, our biochemical and electrophysiological studies using snapin knock-out mice demonstrate that Snapin plays a critical role in modulating neurosecretion by stabilizing the release-ready vesicles.

Key words: exocytosis; neurosecretion; SNARE proteins; synaptic vesicle release; chromaffin cell; catecholamine

\section{Introduction}

The fusion or exocytosis of synaptic vesicles or large dense-core vesicles (LDCVs) with the plasma membrane results in the release of neurotransmitters. $\mathrm{Ca}^{2+}$-triggered exocytosis depends on the presence of a pool of release-ready or primed vesicles that have matured from already docked vesicles (Jahn and Sudhof, 1999; Chen and Scheller, 2001). The priming step corresponds to the assembly of the soluble $N$-ethyl maleimide sensitive factor adaptor protein receptor (SNARE) complex, in which the vesicleassociated v-SNARE protein synaptobrevin (VAMP) interacts with two plasma membrane-associated t-SNARE proteins,

\footnotetext{
Received Aug. 4, 2005; revised Sept. 26, 2005; accepted Sept. 29, 2005.

This work was supported by the intramural research program of the National Institutes of Health (NIH), the National Institute of Neurological Disorders and Stroke (NINDS) (Z.-H.S.), and the Deutsche Forschungsgemeinschaft (J.R.). L.L. and Q.C. are graduate students of the NIH-Shanghai Second Medical University Joint PhD Program in Neuroscience. We thank D. Bruns and H. Arnheiter for helpful discussions; the Electron Microscopy Facility (NINDS, $\mathrm{NIH}$ ) for the electron microscopy procedure; the DNA Sequencing Facility (NINDS, NIH) for DNA sequencing; H. Tian, J.-H. Xu, C. Gerwin, C. Bick, M. Schneider, and J. Hunt for technical assistance; J.-S. Kang for quantification analysis; M. Leenders, P. Zald, C. Gerwin, and B. McNeil for their critical reading of this manuscript; and M. Takahashi for SNARE antibodies.

*J.-H.T. and Z.-X.W. contributed equally to this work.

Correspondence should be addressed to either of the following: Zu-Hang Sheng, Synaptic Function Unit, National Institute of Neurological Disorders and Stroke-National Institutes of Health, Building 35, Room 3B203, 35 Convent Drive, Bethesda, MD 20892-3701, E-mail: shengz@ninds.nih.gov; or Jens Rettig, Physiologisches Institut, Universitaet des Saarlandes, Kirrberger Strasse 8, 66424 Homberg/Saar, Germany, E-mail: jrettig@uniklinik-saarland.de. DOI:10.1523/JNEUROSCI.3275-05.2005

Copyright $\odot 2005$ Society for Neuroscience $\quad$ 0270-6474/05/2510546-10\$15.00/0
}

synaptosomal-associated protein $25 \mathrm{kDa}$ (SNAP-25) and syntaxin, to form a stable SNARE complex (Trimble et al., 1988; Oyler et al., 1989; Bennett et al., 1992; Yoshida et al., 1992; Söllner et al., 1993; Calakos et al., 1994; Fasshauer et al., 1998; Hilfiker et al., 1999). Synaptotagmins, integral $\mathrm{Ca}^{2+}$-binding proteins of the synaptic vesicle membrane, provide $\mathrm{Ca}^{2+}$-dependent regulation of the fusion machinery (Augustine, 2001; Chapman, 2002). The interaction of synaptotagmin with SNAP-25 is essential for dense-core vesicle release in PC12 cells (Zhang et al., 2002; Tucker et al., 2003; Bai et al., 2004). However, the molecular mechanisms underlying regulation of the structural and functional coupling of the calcium sensor with the SNARE-based fusion machinery during priming and maturation remains unclear.

Snapin was first identified as a SNAP-25 binding protein that associates with the SNARE complex and enhances the association of synaptotagmin with the SNARE complex (Ilardi et al., 1999). Injection of the C-terminal half of Snapin (corresponding to the SNAP-25 binding domain) into presynaptic superior cervical ganglion neurons in culture suppresses EPSP amplitude. Snapin is a ubiquitously expressed soluble protein that is present in both cytosol and peripheral membrane-associated fractions (Buxton et al., 2003; Vites et al., 2004; Ruder et al., 2005). The role of Snapin as a modulatory protein in exocytosis may be controlled by second messenger pathways. Protein kinase A (PKA) phosphorylation of Snapin at Ser-50 results in an increased binding of 
synaptotagmin to the SNARE complex and consequently increases exocytosis of LDCVs in chromaffin cells (Chheda et al., 2001). Transfection of EBAG9 (estrogen receptor-binding fragment-associated gene 9) in PC12 cells inhibits in vivo Snapin phosphorylation and decreases regulated exocytosis of LDCVs, probably by reducing the association of Snapin with SNAP-25 (Ruder et al., 2005). Snapin also plays a regulatory role in synaptic transmission in hippocampal "autapses" (Thakur et al., 2004). These results establish Snapin as an important target of PKA and demonstrate that phosphorylation modulates the efficacy of Snapin action on release.

In the present study, we evaluated the role of Snapin in vesicle exocytosis by abolishing snapin expression in mice via homologous recombination. We found that in snapin mutant mice, the association of synaptotagmin-1 with SNAP-25 in brain homogenates was markedly decreased compared with wild-type littermates. Furthermore, using high-time-resolution electrophysiological techniques, we demonstrated that deletion of snapin in cultured chromaffin cells led to a significant reduction of vesicles residing in releasable pools, and that this inhibitory effect could be fully rescued by overexpression of wild-type Snapin in the mutant cells. Thus, our biochemical and electrophysiological studies of snapin knock-out (KO) mice indicate that Snapin is an important modulator of neurosecretion.

\section{Materials and Methods}

Generation of snapin knock-out mice. The snapin null mutation was generated by targeted gene replacement in embryonic stem (ES) cells. A targeting vector was constructed as shown in Figure $1 A$, in which all four coding exons of the snapin gene were replaced by the selection cassette PGKneo [phosphoglycerate kinase (PGK) neomycin resistance gene under the PGK promoter]. The herpes simplex virus-1 thymidine kinase (TK) gene under the PGK promoter (TK cassette) was placed at the end of the long arm of the construct. The vector was linearized and electroporated into ES cell line TC1 (derived from a 129/SvEvTacfBR mouse) and then selected with G418 and $2^{\prime}$-fluoro-2'-deoxy- $1 \beta$-D-arabinofuranosyl-5-iodo-uracil. The culture, electroporation, and selection of TC1 ES cells were performed as described previously (Deng and $\mathrm{Xu}$, 2004). Homologous recombination events were identified by Southern blot screening using a PCR-generated probe corresponding to a fragment outside the recombination site but inside the restriction fragment generated by SpeI digestion (see Fig. $1 \mathrm{~A}$ ). ES cells heterozygous for the targeted mutation were independently microinjected into C57BL/6J blastocysts, generating chimeric mice that transmitted the mutation through the germ line (germline transmission). Heterozygous and knock-out mice were generated and identified by Southern blot (see Fig. $1 B$ ) and PCR amplification. Throughout this study, mouse embryos were obtained by cesarean section of the pregnant females at embryonic day 18 (E18) from timed heterozygous mating. All animal experimentation has been conducted in accordance with the Policies on the Use of Animals and $\mathrm{Hu}$ mans in Neuroscience Research and National Institutes of Health Animal Use Guidelines.

Antibodies, immunoblotting, and immunoprecipitation. Polyclonal Snapin antibody was generated in rabbit against a His-tagged fusion protein corresponding to the mouse Snapin residues 22-78. The antibody was further affinity-purified with a His-Snapin fusion protein. Other antibodies were obtained from commercial sources: Syntaxin1A/B (Santa Cruz Biotechnology, Santa Cruz, CA), $\alpha$-SNAP, $\mathrm{N}$-ethylmaleimide-sensitive factor (NSF), complexin1/2, synapsin I (Synaptic Systems, Göttingen, Germany), and Munc-18 (BD Transduction, San Diego, CA). The monoclonal antibodies against SNAP-25, syntaxin-1, synaptotagmin-1, rab3a, and a polyclonal anti-VAMP-2 antibody were kind gifts from M. Takahashi (Kitasato University, Kanagawa, Japan).

E18 mouse embryo brains from snapin wild-type, heterozygous, and homozygous littermates were homogenized in a lysis buffer containing
50 mm Tris- $\mathrm{HCl}$, pH 7.4, $150 \mathrm{~mm} \mathrm{NaCl}, 1 \%$ Triton X-100, supplemented with a mixture of protease inhibitors (Sigma, St. Louis, MO). The detergent extracts were centrifuged at $15,000 \times g$ for $20 \mathrm{~min}$, and the concentration of the solubilized protein was determined with a BCA assay kit (Pierce, Rockford, IL). For detection of various proteins in brain homogenates, equal amounts $(40 \mu \mathrm{g})$ of brain homogenates were processed for SDS-PAGE and immunoblotted using ECL procedures (Amersham Biosciences, Piscataway, NJ). For multiple detection with different antibodies, blots were first stripped in a solution of $62.5 \mathrm{~mm}$ Tris- $\mathrm{HCl}, \mathrm{pH} 7.5,20$ $\mathrm{mm}$ dithiothreitol, and $1 \%$ SDS for $20 \mathrm{~min}$ at $50^{\circ} \mathrm{C}$ with gentle agitation and then washed with TBS/0.1\% Tween 20 two times ( 15 min each).

For immunoprecipitation, solubilized brain homogenates $(100 \mu \mathrm{g})$ were incubated with $1 \mu \mathrm{g}$ of monoclonal antibodies against SNAP-25, synaptotagmin-1, syntaxin-1, or control mouse IgG (Sigma) in $200 \mu \mathrm{l}$ of TBS with $0.1 \%$ Triton X-100 and protease inhibitors, and incubated on a microtube rotator at $4^{\circ} \mathrm{C}$ for $1 \mathrm{~h}$. Protein A-Sepharose CL-4B resin $(2.5$ mg; Amersham Biosciences) was added to each sample, and the incubation continued for an additional $3 \mathrm{~h}$, followed by three washes with $\mathrm{TBS} / 0.1 \%$ Triton X-100. The immobilized protein complexes were processed for SDS-PAGE and immunoblotting using ECL procedures. For semiquantitative analysis, protein bands detected by ECL were scanned into Adobe Photoshop (Adobe Systems, San Jose, CA), and images were analyzed using Imaging software Gel-Pro 4.5 (Media Cybernetics, Silver Spring, MD). Care was taken during exposure of the ECL film to ensure that all intensity readings were in the linear range of a standard blot detected by the same antibody. The normalized percentage of synaptotagmin coimmunoprecipitated by anti-SNAP- 25 antibody from snapin knock-out mice relative to that from wild-type littermates was calculated using standard curves. Paired Student's $t$ tests were performed, and results are expressed as mean \pm SEM from 11 littermates.

For coimmunoprecipitation with chemically cross-linked brain homogenates, fresh-made brain homogenates were incubated with PBS containing $200 \mu \mathrm{M}$ cross-linker dithiobis[succinimidylpropionate] (DSP) or 3,3'-dithiobis[sulfosuccinimidylpropionate] (DTSSP) (Pierce) for $15 \mathrm{~min}$ at $4^{\circ} \mathrm{C}$ and terminated by incubation with Tris, $\mathrm{pH}$ 7.4, at 40 $\mathrm{mm}$ for another $15 \mathrm{~min}$ at $4^{\circ} \mathrm{C}$, and followed by solubilization with $1 \%$ Triton X-100. Immunoprecipitation was performed overnight at $4^{\circ} \mathrm{C}$ with immobilized anti-Snapin antibody or control IgG in TBS buffer with $0.1 \%$ Triton X-100 and protease inhibitors and washed four times with TBS before analysis by SDS-PAGE.

Immunoisolation of LDCVs. Synaptophysin is a membrane protein of LDCVs in adrenal chromaffin cells. The immunoisolation of LDCVs was performed with synaptophysin antibody-coated magnetic beads. Briefly, goat anti-mouse IgG (Fc fragment specific) (linker; Jackson ImmunoResearch, West Grove, PA) was incubated for $24 \mathrm{~h}$ at $37^{\circ} \mathrm{C}$ on a rotator with M-500 Dynabeads (Dynal, Lake Success, NY) at a ratio of $7 \mu \mathrm{g}$ of linker per $10^{7}$ beads in $0.1 \mathrm{M}$ borate buffer, $\mathrm{pH} 9.5$, at a final concentration of $4 \times 10^{8}$ beads $/ \mathrm{ml}$. The coated beads were washed twice, $5 \mathrm{~min}$ each, in PBS, pH 7.4, with $0.1 \% \mathrm{BSA}$ at $4^{\circ} \mathrm{C}$ on a rotator and incubated for $20 \mathrm{~h}$ in $0.2 \mathrm{M}$ Tris, $\mathrm{pH} 8.5$, with $0.1 \% \mathrm{BSA}$ at room temperature. After washing once for $5 \mathrm{~min}$ in PBS, pH 7.4, with $0.1 \% \mathrm{BSA}$ at $4^{\circ} \mathrm{C}$, the linker-coated beads $(\sim 1-2 \mathrm{mg})$ were incubated with $2 \mu \mathrm{g}$ of anti-synaptophysin monoclonal antibody or control mouse IgG overnight at $4^{\circ} \mathrm{C}$ on a rotator. After incubation, the beads were washed four times ( 5 min each) in PBS, pH 7.4, with $0.1 \%$ BSA at $4^{\circ} \mathrm{C}$ and then resuspended in buffer $\mathrm{A}$ containing PBS, pH 7.4, 2 mM EDTA, and 5\% BSA. One hundred micrograms of PNS (postnuclear supernatant at $2000 \times g$; $10 \mathrm{~min}$ ) from the homogenates of medulla of adult (postnatal day 30 ) mouse adrenal gland were mixed with buffer A containing beads (final reaction volume, $1 \mathrm{ml}$ ) and incubated overnight at $4^{\circ} \mathrm{C}$ on a rotator. After incubation, the beads were collected with a magnetic device (Dynal) and washed five times in buffer A for 15 min each and once for 5 min in PBS with $0.1 \%$ BSA. After the final wash, the beads were saved as bound fractions and were subsequently analyzed by immunoblotting for detection of Snapin and other organelle markers.

Preparation and ultrastructural analysis of embryonic mouse chromaffin cells. After cesarean section, embryonic adrenal glands were dissected, placed in filtered Locke's solution (in mM: $154 \mathrm{NaCl}, 5.6 \mathrm{KCl}, 5.0 \mathrm{HEPES}$, $3.6 \mathrm{NaHCO}_{3}$, and 5.6 glucose), and cleaned free of connective tissue. The 
glands were incubated with $0.2 \mathrm{ml}$ of papain solution (see below) at $37^{\circ} \mathrm{C}$ for $45 \mathrm{~min}$ with gentle shaking, followed by the addition of $150 \mu \mathrm{l}$ of inactivating solution (see below) for $10 \mathrm{~min}$ at $37^{\circ} \mathrm{C}$. The solution was then carefully replaced by $70 \mu \mathrm{l}$ of culture medium (see below), and the glands were triturated gently through a $200 \mu$ l pipette tip. Seventy microliters of cell suspension were plated on plastic chamber slides (one embryo/chamber), and the cells were allowed to settle for $15 \mathrm{~min}$ before supplementing with culture medium. The cells were incubated at $37^{\circ} \mathrm{C}$ and $5 \% \mathrm{CO}_{2}$ and used on the second day for electron microscopy (EM) analysis. Papain solution contained $250 \mathrm{ml}$ of DMEM medium (high glucose, Glutamax I, without sodium-pyruvate; Invitrogen, Carlsbad, CA) supplemented with $50 \mathrm{mg}$ of L-cysteine (Sigma), $2.5 \mathrm{ml}$ of $0.1 \mathrm{M}$ $\mathrm{CaCl}_{2}, 2.5 \mathrm{ml}$ of $50 \mathrm{~mm} \mathrm{EDTA}$, and $20-25 \mathrm{U} / \mathrm{ml}$ papain (Worthington, Freehold, NJ), was equilibrated with $5 \% \mathrm{CO}_{2}$ in $\mathrm{O}_{2}$ for $10-20 \mathrm{~min}$, and was then filter-sterilized before use. Inactivating solution consisted of $225 \mathrm{ml}$ of DMEM supplemented with $25 \mathrm{ml}$ of heat-inactivated fetal calf serum (Invitrogen), $625 \mathrm{mg}$ of albumin (Sigma), and $625 \mathrm{mg}$ of trypsin inhibitor (Sigma). Culture medium consisted of DMEM (100 ml) supplemented with $1 \mathrm{ml}$ of $100 \times$ penicillin/streptomycin (Invitrogen) and 1 $\mathrm{ml}$ of $100 \times$ insulin-transferrin-selenium-X (Invitrogen).

Isolated chromaffin cells ( $2 \mathrm{~d}$ in vitro) were fixed with $4 \%$ glutaraldehyde in $0.1 \mathrm{~N}$ sodium cacodylate buffer at $\mathrm{pH} 7.4$ for $1 \mathrm{~h}$ at room temperature and then stored in fixative at $4^{\circ} \mathrm{C}$. The samples were then treated with Osmium tetroxide, en bloc mordanted with uranyl acetate, dehydrated through a series of graded ethanol, and embedded in epoxy resins. Thin sections were stained with uranyl acetate and lead citrate (EM Facility, National Institute of Neurological Disorders and Stroke, National Institutes of Health). The sections were examined on a JEOL (Akishima, Japan) 1200 EX electron microscope, and digital images were captured with a CCD camera system (XR-100; Advanced Microscopy Techniques, Danvers, MA). For each genotype, the distribution of LDCVs was analyzed in sections of 16-17 randomly selected chromaffin cells from four different animals at low magnification and subsequently examined at $30,000 \times$ magnification. LDCVs were recognized by their round, dense core and had a diameter of $\sim 120 \mathrm{~nm}$. The distances between the center of chromaffin granules and the plasma membrane were measured using NIH Image J.

Electrophysiological experiments. All electrophysiological experiments were performed on mouse chromaffin cells in primary culture. The cells were prepared as described previously (Sorensen et al., 2002). Briefly, the mice were prepared after cesarean section on E18-E19. Pregnant mothers were decapitated after cervical dislocation, and embryos were decapitated and placed on ice. The adrenal glands were rapidly removed and placed in cold Locke's solution. The glands were then incubated for 20 min in a DMEM solution containing $35 \mathrm{U} / \mathrm{ml}$ papain (Roche, Indianapolis, IN). The glands were then washed in an inactivating solution (DMEM plus 10\% BSA) after the removal of the papain solution. After 4 min in the inactivating solution, the glands were triturated and plated on glass coverslips. After $30 \mathrm{~min}, 3 \mathrm{ml}$ of DMEM was added to the wells containing the coverslips, and the cells were incubated for up to $4 \mathrm{~d}$ at $37^{\circ} \mathrm{C}$ in DMEM gassed with $8 \% \mathrm{CO}_{2}$.

Snapin KO (-/-) mice were identified by PCR using specific oligonucleotides. Wild-type snapin was introduced into snapin knock-out chromaffin cells by infection with a modified form of the Semliki Forest Virus containing a gene encoding Snapin with GFP fused to its $\mathrm{N}$ terminus. Snapin KO chromaffin cells were infected with the virus 5-8 h before use. Cells expressing Snapin were identified by the presence of green fluorescence (excitation wavelength, $488 \mathrm{~nm}$ ).

Capacitance measurements of chromaffin cells were performed during whole-cell recordings using an EPC9 amplifier (Heka Electronics, Lambrecht, Germany). A sine plus DC protocol was applied using the Lockin amplifier of the Pulse program (Heka Electronics). Chromaffin cells were voltage clamped at a holding potential of $-70 \mathrm{mV}$, and a sine wave voltage command with an amplitude of $30 \mathrm{mV}$ was applied. The intracellular solution contained the following (in mM): 105 Cs-aspartate, 2 MgATP, 0.3 GTP, 33 HEPES, $0.4 \mathrm{Mg}^{2+}$-fura- $2 \mathrm{AM}, 4 \mathrm{CaCl}_{2}, 0.4$ fura- 4 $\mathrm{AM}$, and $5 \mathrm{NP}-\mathrm{EGTA}$, adjusted to $\mathrm{pH} 7.2$ using $\mathrm{CsOH}$ (osmolarity, $307 \pm$ $4 \mathrm{mOsm})$. The intracellular $\mathrm{Ca}^{2+}$ concentration before the flash was between 300 and $500 \mathrm{~nm}$. The extracellular solution contained the fol- lowing (in mM): $145 \mathrm{NaCl}, 2.4 \mathrm{KCl}, 10 \mathrm{HEPES}, 4 \mathrm{MgCl}_{2}, 1 \mathrm{CaCl}_{2}$, and 10 glucose, $\mathrm{pH} 7.4$ (310-315 mOsm).

For ratiometric determination of intracellular calcium, an in vivo ratiometric calibration was performed in chromaffin cells using patch pipettes filled with solutions of known calcium concentrations. The resulting plot of ratio versus $\mathrm{Ca}^{2+}$ concentration was fit with a two-bindingsite model, allowing for extrapolation of all ratios to their calcium value (Voets et al., 2001a). Secretion was elicited by an increase in intracellular calcium that resulted from flash photolysis of calcium bound to NPEGTA. UV flashes were generated by a Rapp Optoelektronik (Hamburg, Germany) lamp. Trains of light at 350 and $380 \mathrm{~nm}$ were obtained via a monochromator (Till Photonics, Planegg, Germany). The resulting fluorescence was acquired by a photodiode (Till Photonics).

Carbon fiber electrodes used for amperometry were produced as follows. Carbon fibers ( $5 \mu \mathrm{m}$ diameter) were glued to copper cannulas using a conducting carbon paste (Electrodag 5513; Bavaria Elektronik, Rosenheim, Germany) and were glued inside a glass pipette. The pipettes were then pulled with a conventional puller. The carbon fiber extending beyond the pulled pipette tip was coated with a cathodal paint by electrolysis (\#2934788; BASF). The assembly was then baked for $20 \mathrm{~min}$ at $50^{\circ} \mathrm{C}$. The junction between the fiber and the glass was sealed with Sylgard and baked again at $50^{\circ} \mathrm{C}$. Before use, the carbon fibers were broken off to expose the tip for recording. The electrode was connected to the head stage of an EPC7 patch-clamp amplifier (Heka Electronics) and a holding potential of $+800 \mathrm{mV}$ was applied in the voltage-clamp mode. After the whole-cell configuration was achieved, the carbon fiber was positioned so that it lightly touched the cell that was being recorded. Catecholamines contacting the carbon fiber were immediately oxidized, producing a current on the pipette that was countered by the patch clamp, and allowing recording of catecholamine release as a measure of the amperometric current. Thus, capacitance and amperometry were performed on the same chromaffin cell simultaneously.

\section{Results}

\section{Targeted disruption of the snapin gene}

Inactivation of the snapin gene in TC1 ES cells from 129/ SvEvTacfBR mice was achieved by replacing all four coding exons with a PGKneo gene cassette (Fig. 1A). ES cells heterozygous for the targeted mutation were microinjected into C57BL/6 blastocysts to generate chimeric mice. Chimeric male mice were crossed with C57BL/6 females to obtain germline transmission of the mutant allele. Correct gene targeting in ES cells and transmission of the mutant allele to the progeny were verified by Southern blot analysis (Fig. $1 B$ ). Because the inserted PGKneo cassette introduced a new SpeI site, Southern blot analysis revealed a novel 5.9 $\mathrm{kb}$ DNA fragment corresponding to the interrupted gene to replace a $10.2 \mathrm{~kb}$ fragment of the wild-type snapin gene.

Mice heterozygous for the snapin mutation were viable, fertile, and phenotypically indistinguishable from wild-type littermates. Homozygous animals were born but inevitably died within several hours of birth, consistent with a perinatal lethal phenotype. At E17.5-E18.5, mutants were recovered close to the expected Mendelian ratio $(0.24,0.46,0.30$ homozygous, heterozygous, and wild-type, respectively; $n=268$ ). Despite this perinatally lethal phenotype, homozygous snapin $\mathrm{KO}$ mice showed no obvious changes in structure and cytoarchitecture of the brain and adrenal gland (data not shown) or at the ultrastructural level of synapses of the hippocampus (supplemental Fig. 1A, available at www.jneurosci.org as supplemental material).

Western blot analysis of brain homogenates showed that Snapin expression was abolished in homozygous KOs and significantly reduced in heterozygous mutants (Fig. $1 C$ ). The absence of Snapin expression did not affect the expression of a large variety of proteins involved in synaptic vesicle exocytosis. These included plasma membrane t-SNAREs (SNAP-25, syntaxin-1A/B), intrinsic membrane proteins of synaptic vesicles (synaptobrevin/ 
A
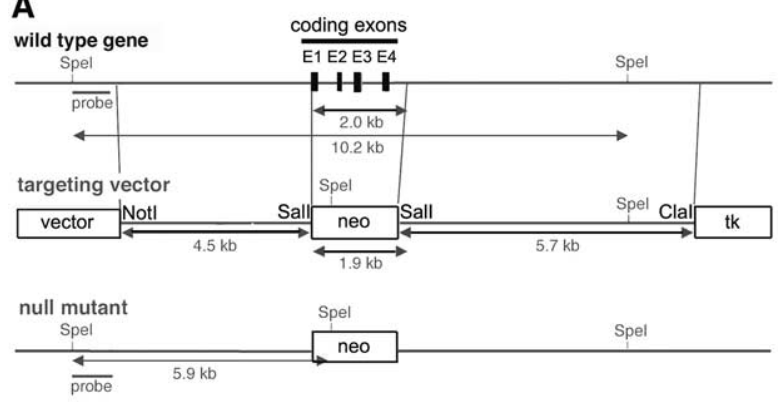

B

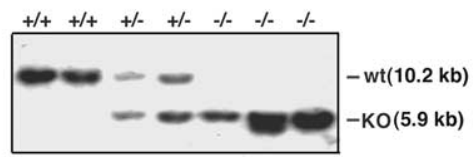

C

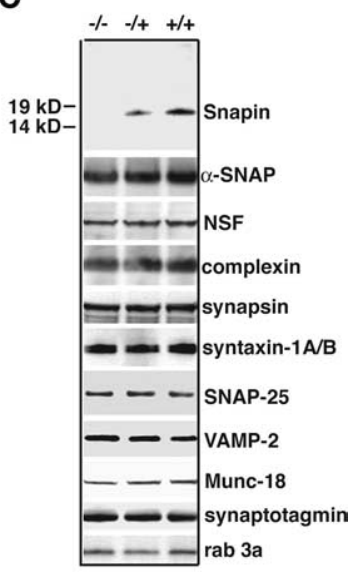

Figure 1. Generation of mice lacking snapin. $\boldsymbol{A}$, Maps of the wild-type snapin gene, the respective targeting vector, and the resulting mutant gene. A genomic clone of the snapin gene containing all four coding exons E1-E4 (boxes in top diagram) was used to generate a targeting vector (middle diagram), which was used for homologous recombination in embryonic stem cells (bottom diagram). Restriction enzyme sites (Spel, Notl, Sall, and Clal) and position of the probe (bar) used for Southern blot analysis are indicated. Neo, Neomycin resistance gene; TK, thymidine kinase gene. $\boldsymbol{B}$, Southern blot analysis of the snapin KO mutation in mice. Spel-digested genomic DNA isolated from mouse tails of wild-type (wt) $(+/+)$, heterozygous $(+/-)$, and homozygous ( $-1-$ ) animals was hybridized with the probe detecting the DNA fragments at 10.2 and $5.9 \mathrm{~kb}$ for the wild-type and mutant alleles, respectively. C, Immunoblot analysis of Snapin and other basic and regulatory components of synaptic vesicle release machinery. Equal amounts of brain homogenates $(40 \mu \mathrm{g})$ from the E18 embryos of all genotypes were blotted with antibodies as indicated.

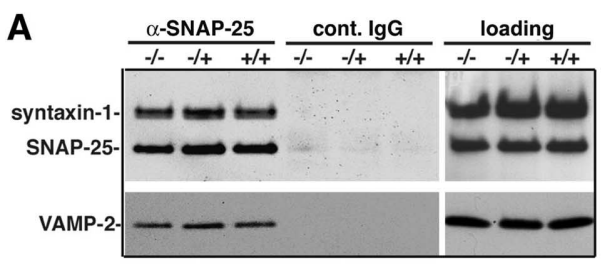

C

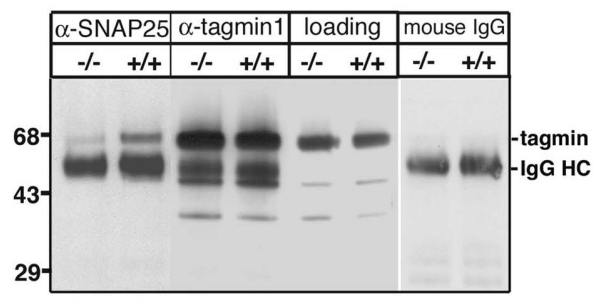

Figure 2. Effect of snapin knock-out on the association of SNAP-25 with synaptotagmin-1. A, Immunoprecipitation of the native SNARE complex. One microgram of anti-SNAP- 25 antibody ( $\alpha$-SNAP-25) coimmunoprecipitated syntaxin- 1 and VAMP-2 from solubilized mouse brain homogenates of snapin wild-type $(+/+)$, heterozygous $(-/+)$, and homozygous $(-/-)$ mutants. Coimmunoprecipitates were analyzed by sequential immunoblotting of the same membrane after stripping of previous antibodies. Mouse lgG (cont. IgG) was used as an immunoprecipitation control. B, C, Decreased association of SNAP-25 with synaptotagmin-1 in snapin K0 mutant. Brain homogenates (100 $\mu \mathrm{g})$ from wild-type and homozygous K0 littermates were immunoprecipitated by $1 \mu \mathrm{g}$ of indicated antibodies or control lgG followed by immunoblotting with anti-syntaxin- 1 and antiSNAP-25 (B) or anti-synaptotagmin-1 $(\boldsymbol{C})$ antibodies. Note that a significant decrease in the association of SNAP-25 with synaptotagmin-1 was observed in the absence of Snapin, whereas the amount of the SNARE complex (syntaxin, SNAP-25, and VAMP2) remains unchanged. Loading lanes represent $15 \%$ of homogenates used for each immunoprecipitation. IgG HC, IgG heavy chain. $D$, Normalized amounts of synaptotagmin-1 coimmunoprecipitated by anti-SNAP-25 antibody from both snapin wild-type $(+/+)$ and $\mathrm{KO}(-/-)$ brain homogenates. A $34 \pm 3 \%$ reduction was observed for the amount of synaptotagmin-1 coprecipitated by anti-SNAP-25 antibody from KO relative to that from wild-type homogenates (mean \pm SEM from 11 littermates). A two-tailed Student's $t$ test for paired data was used; ${ }^{* *} p<0.01$.

VAMP-2 and synaptotagmin-1), proteins implicated in the synaptic vesicle cycle (synapsin 1 and rab 3a), NSF and its cofactor $\alpha$-SNAP for disassembly of the cis-SNARE complex, and other SNARE regulatory proteins (Munc-18 and complexin). These results indicate that snapin deletion does not result in any apparcomplex. ent compensatory changes in the expression of known proteins that are required for presynaptic function.

\section{Decreased association of} synaptotagmin-1 with SNARE proteins in the absence of Snapin

Our previous in vitro biochemical study demonstrated that excess recombinant Snapin significantly enhances the immunoprecipitation of synaptotagmin-1 with the SNARE complex, suggesting that Snapin modulates the sequential interactions of SNARE proteins and synaptotagmin-1 (Ilardi et al., 1999; Chheda et al., 2001). In the present study, we evaluated this hypothesis using brain homogenates prepared from snapin knock-out mice. No detectable change in the expression levels of synaptotagmin-1 and the three SNARE components (SNAP25, syntaxin-1A/B, and synaptobrevin/ VAMP-2) was observed in snapin homozygous $(-/-)$ homogenates compared with wild-type $(+/+)$ control homogenates (Fig. $1 C)$. In addition, the anti-SNAP-25 antibody equally coimmunoprecipitated SNAP-25, syntaxin-1, and VAMP-2 from solubilized mouse brain homogenates of snapin wild-type $(+/+)$, heterozygous $(-/+)$, and homozygous $(-/-)$ mutants (Fig. 2A), suggesting that the formation of the SNARE complex is not affected by deletion of snapin. Consistent with our hypothesis, after coimmunoprecipitation with either anti-synaptotagmin-1 or antiSNAP-25 antibody (Fig. 2B, C), we consistently detected a marked reduction in the association of SNAP-25 and synaptotagmin-1 in brain homogenates of snapin $\mathrm{KO}$ mice when compared with wild-type littermates. Synaptotagmin-1 was precipitated in equal amounts from both types of homogenates by an antisynaptotagmin-1 antibody, and no immunoprecipitation was observed in the presence of a mouse control IgG (Fig. $2 A-C$ ). Quantitative analysis revealed that the anti-SNAP-25 antibody immunoprecipitated $34 \pm 3 \%$ less synaptotagmin-1 from mutant $(-/-)$ brain homogenates than from wild-type $(+/+)$ (mean \pm SEM from 11 littermates; $p<0.01)$. Thus, consistent with our previous biochemical observations with recombinant proteins, this study using snapin knock-out mice demonstrates that Snapin modulates the interaction of synaptotagmin-1 with SNARE proteins in vivo without affecting the formation of the SNARE

To further test our hypothesis that Snapin plays a role in the structural coupling of the calcium sensor synaptotagmin-1 with SNAREs during LDCV priming, we performed three lines of bio- 
chemical experiments. First, in vitro binding studies with recombinant proteins showed that His-tagged Snapin interacts with both glutathione $S$-transferase (GST)-synaptotagmin-1 and GSTSNAP-25 (Fig. 3A). Second, anti-Snapin antibody specifically coimmunoprecipitated synaptotagmin-1 from chemically cross-linked brain homogenates (Fig. 3B), providing biochemical evidence that endogenous Snapin is able to associate synaptotagmin-1. Furthermore, to address the specificity of the role of Snapin in neuroexocytosis, we immunoisolated LDCVs from homogenates of mouse adrenal gland with magnetic beads (Dynabeads) coated with an antibody against the vesicle membrane protein synaptophysin. Our studies found that Snapin was associated with the purified LDCVs along with other LDCV markers, including VAMP2, synaptotagmin-1, and VMAT2 (vesicular monoamine transporter) (Fig. 3C). In contrast, there were no detectable markers of various cellular organelles including p115 (Golgi), EEA1 (endosomes), and cytochrome $c$ (mitochondria) in the preparation, indicating high purity of the immunoisolated LDCVs. The relative enrichment of LDCV-associated Snapin was further estimated using a standard curve of immunoblotting by the same panel of antibodies. Approximately 15\% of total Snapin in the homogenates of the adrenal gland was associated with the purified LDCVs, which is comparable with the relative enrichment of the LDCV membrane proteins VAMP2 (30\%) and synaptotagmin-1 (19\%) under our purification conditions. Taking into account that $>50 \%$ of the LDCVs are found within a distance of up to $200 \mathrm{~nm}$ from the plasma membrane (Speidel et al., 2005), these data demonstrate that Snapin is sufficiently enriched in a restricted compartment (LDCVs) to perform its modulatory function during LDCV priming.

\section{Reduced secretion of LDCVs from snapin KO chromaffin cells}

The physiological role of Snapin in synaptic vesicle exocytosis was previously examined by both microinjection of the Snapincarboxyl half (containing the coiled-coil SNAP-25 binding domain) into presynaptic superior cervical ganglion neurons in culture (Ilardi et al., 1999) and by overexpression of Snapin in cultured chromaffin cells (Chheda et al., 2001) and hippocampal neurons (Thakur et al., 2004). The generation of snapin knockout mice allowed us to examine the phenotype of $\mathrm{Ca}^{2+}$-regulated neuroexocytosis in the absence of Snapin and to rescue any observed phenotypes by reintroduction of Snapin into knock-out cells in vitro, which together are critical in addressing the specific role and mechanism of Snapin function in neuroexocytosis.

We used cultured embryonic chromaffin cells as a model for neuroexocytosis, because they use the same vesicle fusion machinery as neurons (Rettig and Neher, 2002) and were confirmed to express Snapin by single-cell reverse transcription-PCR (sup- plemental Fig. $1 B$, available at www.jneurosci.org as supplemental material). Two independent methods for measuring vesicle fusion and catecholamine release from LDCVs were applied simultaneously to assess the role of Snapin in neuroexocytosis. Vesicle fusion with the membrane was recorded by high-timeresolution capacitance measurements, whereas catecholamine release was determined using carbon fiber amperometry. These two methods are complementary, because they determine vesicle fusion and transmitter release, respectively. Secretion in chromaffin cells was elicited by photolytic uncaging of $\mathrm{Ca}^{2+}$ from NP-EGTA by a flash of UV light, which produced a step-like increase in intracellular calcium. The flash was followed by a series of illuminations alternating between 350 and $380 \mathrm{~nm}$, which allowed ratiometric determination of the calcium concentration. The duration of these illuminations was selected to maintain relatively constant calcium concentrations, because the illumination at 350 and $380 \mathrm{~nm}$ also led to photolytic release of $\mathrm{Ca}^{2+}$.

Under control conditions, the flash protocol led to a rapid burst of catecholamine release ("exocytotic burst") followed by a slower, more linear release phase ("sustained component") (Fig. $4 \mathrm{~A}$, middle). According to the present model, the exocytotic burst represents the fusion of fusion-competent vesicles out of the releasable pool, whereas the sustained component represents recruitment of new granules followed by fusion (Rettig and Neher, 2002). Measurements from 47 wild-type E19 chromaffin cells yielded an average size of $331 \pm 23 \mathrm{fF}$ for the exocytotic burst 
A
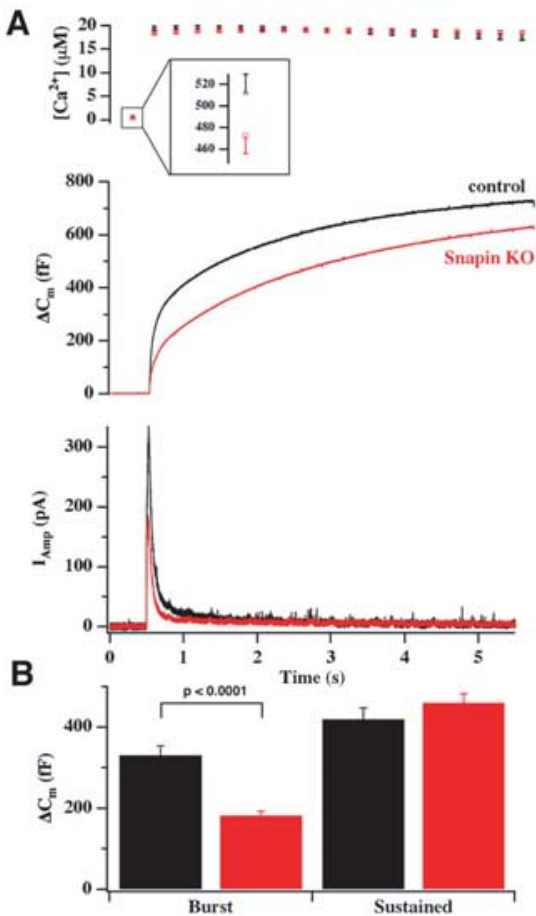

C
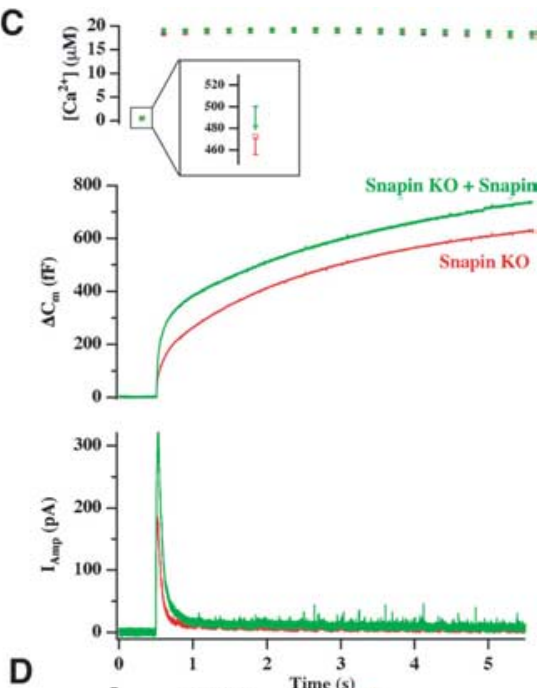

D

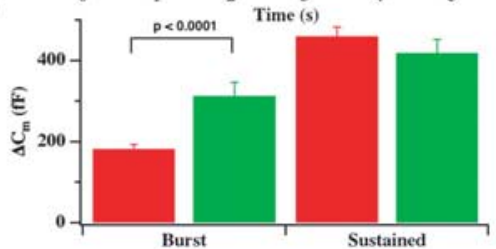

Figure 4. Absence of Snapin leads to a reduction in LDCV exocytosis from adrenal chromaffin cells after flash photolysis of caged calcium. $A$, Averaged calcium concentration $\left(\left[\mathrm{Ca}^{2+}\right]_{\mathrm{i}} ;\right.$ top), capacitance $\left(\Delta C_{\mathrm{m}} ;\right.$ middle), and amperometric responses $\left(I_{\mathrm{Amp}}\right.$ i bottom) in response to flash-photolysis of NP-EGTA in control cells (47 cells from 7 animals; black line and symbols) and snapin KO cells (112 cells from 12 animals; red line and symbols). Both capacitance and amperometric traces display a rapid, burst-like increase within the first second after the flash, followed by a slower sustained phase of secretion. The inset in the top panel shows the basal $\left[\mathrm{Ca}^{2+}\right]_{\mathrm{i}}$ before the flash, which was not significantly different between the two groups. $\boldsymbol{B}$, Kinetic analysis of the experiment shown in $A$. Snapin $\mathrm{KO}$ cells show a selective reduction of the exocytotic burst ( $p<0.0001$; Mann-Whitney $U$ test), whereas the sustained component is unaffected (for details, see Table 1). C, Averaged calcium concentration $\left(\left[\mathrm{Ca}^{2+}\right]_{j}\right.$; top), capacitance $\left(\Delta C_{\mathrm{m}} ;\right.$ middle), and amperometric responses $\left(I_{\text {Amp }} ;\right.$ bottom $)$ in response to flash-photolysis of NP-EGTA in snapin KO cells (112 cells from 12 animals; red line and symbols) and snapin K0 cells infected with Snapin-GFP ( 34 cells from 8 animals; green line and symbols). The inset in the top panel shows the basal $\left[\mathrm{Ca}^{2+}\right]_{\mathrm{i}}$ before the flash, which was not significantly different between the two groups. $\boldsymbol{D}$, Kinetic analysis of the experiment shown in $\boldsymbol{C}$. Reintroduction of Snapin into snapin $\mathrm{KO}$ cells resulted in a complete recovery of the exocytotic burst size to control values (Table 1) (see $\boldsymbol{A}$ and $\boldsymbol{B}$ for comparison; $\boldsymbol{p}<0.0001$ ), demonstrating the specificity of the observed effect by Snapin. Error bars represent SEM.

Table 1. Detailed parameters of capacitance measurements from snapin wild-type and $\mathrm{K} 0$ mice and the Snapin rescue

\begin{tabular}{llcl}
\hline & Wild type $(+/+)(n=47)$ & Snapin K0 $(-/-)(n=112)$ & Rescue $(n=34)$ \\
\hline RRP (fF) & $196.3 \pm 18.2$ & $96.7 \pm 9.5$ & $210.1 \pm 32.2$ \\
SRP (fF) & $134.7 \pm 11.9$ & $84.9 \pm 5.3$ & $105.1 \pm 10.3$ \\
Sustained (fF) & $419.3 \pm 28.1$ & $460.0 \pm 22.2$ & $418.1 \pm 33.4$ \\
\hline
\end{tabular}

Average sizes of RRP, SRP, and sustained component (Sustained) in wild-type (+/+) and homozygous (-/ - ) snapin K0 mice as well as from overexpression of Snap in snapin $\mathrm{KO}$ cells (Rescue) are shown. Exocytosis was triggered by flash photolysis of the $\mathrm{Ca}^{2+}$-cage NP-EGTA. The number of cells measured is given in parentheses.

and $419 \pm 28 \mathrm{fF}$ for the sustained component (Fig. $4 A, B$ ). In contrast, in 112 cells obtained from snapin $\mathrm{KO}$ littermates, the exocytotic burst was reduced by $\sim 45 \%(182 \pm 11 \mathrm{fF} ; p<0.0001)$, whereas the sustained component remained unchanged $(460 \pm$ $22 \mathrm{fF}$ )(Table 1). Consistent with this observation, the current measured by the carbon fiber amperometry electrode $\left(I_{\mathrm{Amp}}\right)$ was also significantly smaller in the snapin KO chromaffin cells, compared with that observed in the cells from wild-type littermates (Fig. $4 A$, bottom), demonstrating that the observed effect was a result of a decreased exocytosis and not increased endocytosis. The intracellular calcium concentrations before and during the secretion episode were not significantly different for the wildtype and snapin KO cells (Fig. $4 A$, top). In addition, we performed the capacitance measurements on chromaffin cells from
Snapin heterozygous mutant mice and found no significant difference in the LDCV secretion compared with that of the control cells (data not shown). We hypothesize that because Snapin is relatively enriched in LDCVs (Fig. 3C) and functions as a modulatory but not structural and essential component of exocytotic machinery, a mildly reduced expression of Snapin in heterozygous mutant cells would not have a significant impact on LDCV exocytosis.

To confirm that the observed difference between wild-type and snapin $\mathrm{KO}$ chromaffin cells was attributable to the absence of Snapin, we compared secretion between snapin $\mathrm{KO}$ chromaffin cells and snapin "Rescue" chromaffin cells obtained from the same mouse, in which snapin had been reintroduced using a modified Semliki forest virus carrying the mouse snapin gene. Snapin KO cells overexpressing the snapin gene exhibited a larger burst phase of release and greater total release than uninfected snapin KO cells but displayed a similar sustained release phase (Fig. 4C, middle). Comparison of the amperometric currents confirmed that the burst of catecholamine secretion is greater in those snapin KO cells expressing Snapin (Fig. $4 C$, bottom). Separation of the burst and sustained phases using triple exponential fits (Fig. 4D) indicates that the reintroduction of Snapin into snapin KO cells led to a recovery of the burst amplitude back to control values $(312 \pm 34 \mathrm{fF} ; n=34)$, whereas the sustained release phase remained unaffected. These results show that deletion of snapin in adrenal chromaffin cells leads to a selective reduction in the size of the exocytotic burst. Reintroduction of Snapin reverses this deficit, demonstrating the specificity of the observed burst reduction after snapin deletion. In both cases, intracellular calcium levels were comparable (Fig. $4 C$, top), indicating that the results are not likely to be attributable to alteration of calcium buffering, influx, or availability.

In principle, the reduced exocytotic burst in snapin KO chromaffin cells could be attributable to either a reduced size of the pool of releasable vesicles or to a reduced $\mathrm{Ca}^{2+}$ sensitivity of the individual releasable vesicle. To distinguish between these possibilities, we performed the recently developed calcium ramp experiments (Sorensen et al., 2002). We slowly increased the calcium concentration in a ramp-like manner using a sequence of UV illuminations similar to that used to maintain $\mathrm{Ca}^{2+}$ at high levels following a flash. This resulted in a slow sigmoid increase in $\mathrm{Ca}^{2+}$ concentration (Fig. $5 \mathrm{~A}$, top), allowing determination of the $\mathrm{Ca}^{2+}$ concentration at which secretion begins. Although secretion in the snapin $\mathrm{KO}$ cells was significantly lower than that of wild-type cells, the threshold for secretion was the same in both groups (Fig. 5A, bottom). Secretion is biphasic, consisting of a 

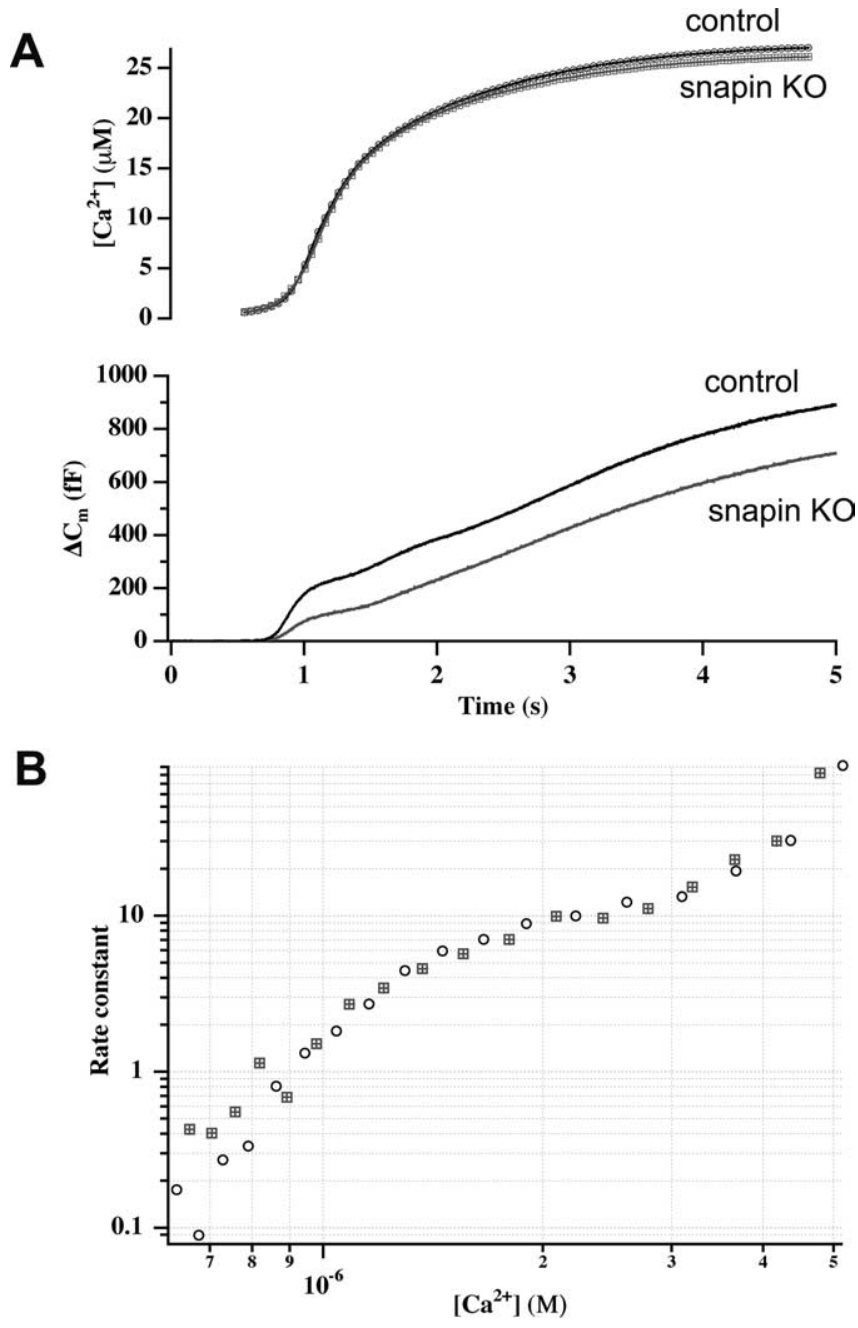

Figure 5. Reduction in exocytosis in snapin $\mathrm{KO}$ cells is not attributable to a change in the $\mathrm{Ca}^{2+}$ dependence of exocytosis. $A$, Calcium ramp experiments were performed by slow release of $\mathrm{Ca}^{2+}$ from NP-EGTA using weak UV-illumination. Membrane capacitance and $\mathrm{Ca}^{2+}$ concentration were monitored simultaneously during the $5 \mathrm{~s}$ of stimulation. In agreement with the flash experiments (Fig. 4), snapin KO cells displayed a smaller secretion than control cells at all calcium concentrations. B, Double logarithmic plot of the rate constant versus calcium for 27 control cells (circles; $n=2$ ) and 26 snapin $\mathrm{KO}$ cells (squares; $n=2$ ). The curves are identical. Neither the $\mathrm{Ca}^{2+}$ sensitivity (threshold) nor the $\mathrm{Ca}^{2+}$ cooperativity (slope) of secretion is altered in the absence of Snapin.

rapid phase, which comprises the readily releasable pool, followed by a sustained phase. Consistent with the observation in flash experiments, the rapid phase was smaller in snapin $\mathrm{KO}$ cells (Fig. $5 A$, bottom). The size of the readily releasable pool was determined from both curves, using the method introduced by Sorensen et al. (2002). The size of the remaining pool was calculated by subtracting the number of fused vesicles from the estimated total pool size. Vesicle fusion was divided by the remaining pool size to arrive at a rate constant for secretion, which is plotted versus the calcium concentration (Fig. 5B). No differences were noted in the calcium dependence of the secretion rate between the wild-type and the snapin KO cells. These results demonstrate that neither the calcium threshold nor the calcium dependence of secretion is altered in the absence of Snapin. Thus, the reduction in the exocytotic burst observed in both flash and $\mathrm{Ca}^{2+}$ ramp experiments is exclusively caused by a reduced number of vesicles residing in the releasable pools.
Normal morphological docking of LDCVs in chromaffin cells in the absence of Snapin

Neuroexocytosis of LDCVs in chromaffin cells includes multiple steps of vesicle docking, subsequent priming, and final fusion events. Docking is considered here to be the physical attachment of vesicles to the plasma membrane and can be observed with electron microscopy (morphological docking). Priming is thought to be the subsequent step in the maturation process in which the docked vesicle becomes fusion-competent in response to $\mathrm{Ca}^{2+}$ signal (Ashery et al., 2000). Primed vesicles usually represent only a small subset of docked vesicles. The electrophysiological data above demonstrated that deletion of snapin leads to a reduced size of the releasable pool. In principle, this could either be a result of a reduction in the priming process or to a defect in any process upstream of priming (e.g., docking). To distinguish between these possibilities, we performed electron microscopic analysis of adrenal chromaffin cells isolated from wild-type and snapin null mutant E18 littermates. As reported previously for embryonic mouse chromaffin cells (Voets et al., 2001b; Sorensen et al., 2003), a large percentage of vesicles were found aligned with the plasma membrane in both wild-type and snapin mutant cells, especially along the plasma membrane in contact with an adjacent cell (Fig. 6A,B). By measuring the distance from the center of the vesicles to the plasma membrane as a quantitative index, we further evaluated the morphological characteristics of docking in both wild-type and mutant cells. Our analysis demonstrated no significant differences between these groups either in the distribution of the vesicles relative to the plasma membrane (Fig. 6D) or in the total number of vesicles per cell section (Fig. $6 E$ ), demonstrating that Snapin is not directly involved in either biogenesis or morphological docking of LDCVs in chromaffin cells. Thus, we can conclude that the observed reduction of secretion in snapin $\mathrm{KO}$ chromaffin cells is exclusively caused by a reduced pool of release-ready vesicles. Because the sustained component, which represents a readout for the priming rate (Rettig and $\mathrm{Ne}$ her, 2002), is unaltered (Fig. 4A), Snapin must act by slowing the depriming rate, most likely by stabilizing the structural coupling of synaptotagmin to the SNARE complex, a critical step for maturation or priming of docked vesicle for fusion. This assumption is supported by our biochemical observations that the specific association of synaptotagmin-1 with the SNARE complex was enhanced by recombinant Snapin in vitro (Ilardi et al., 1999; Chheda et al., 2001) and was impaired in brain homogenates of snapin knock-out mice (Fig. 2B-D).

\section{Discussion}

Our study demonstrates that Snapin is a necessary modulatory protein that plays a nonredundant function in neurosecretion. Deletion of snapin did not result in significant changes in the expression levels of neuronal SNARE proteins, other known regulatory proteins of release, or the formation of the neuronal SNARE complex. However, there was a remarkable effect on the association of SNAP-25 with synaptotagmin, a critical step in the structural coupling of the calcium sensor to the SNARE-based fusion machinery (Zhang et al., 2002; Tucker et al., 2003; Bai et al., 2004). Our current studies provide five lines of evidence that Snapin plays a modulatory role in LDCV release: (1) the reduced secretion in the absence of snapin could be rescued within $4 \mathrm{~h}$ after the reintroduction of the snapin gene into the mutant cells, strongly arguing against an unspecific effect or a nonexocytotic function; (2) our ultrastructural study of mutant chromaffin cells demonstrated that neither a significant defect in the morphological docking of LDCVs nor deficits in the biogenesis of chromaf- 
a

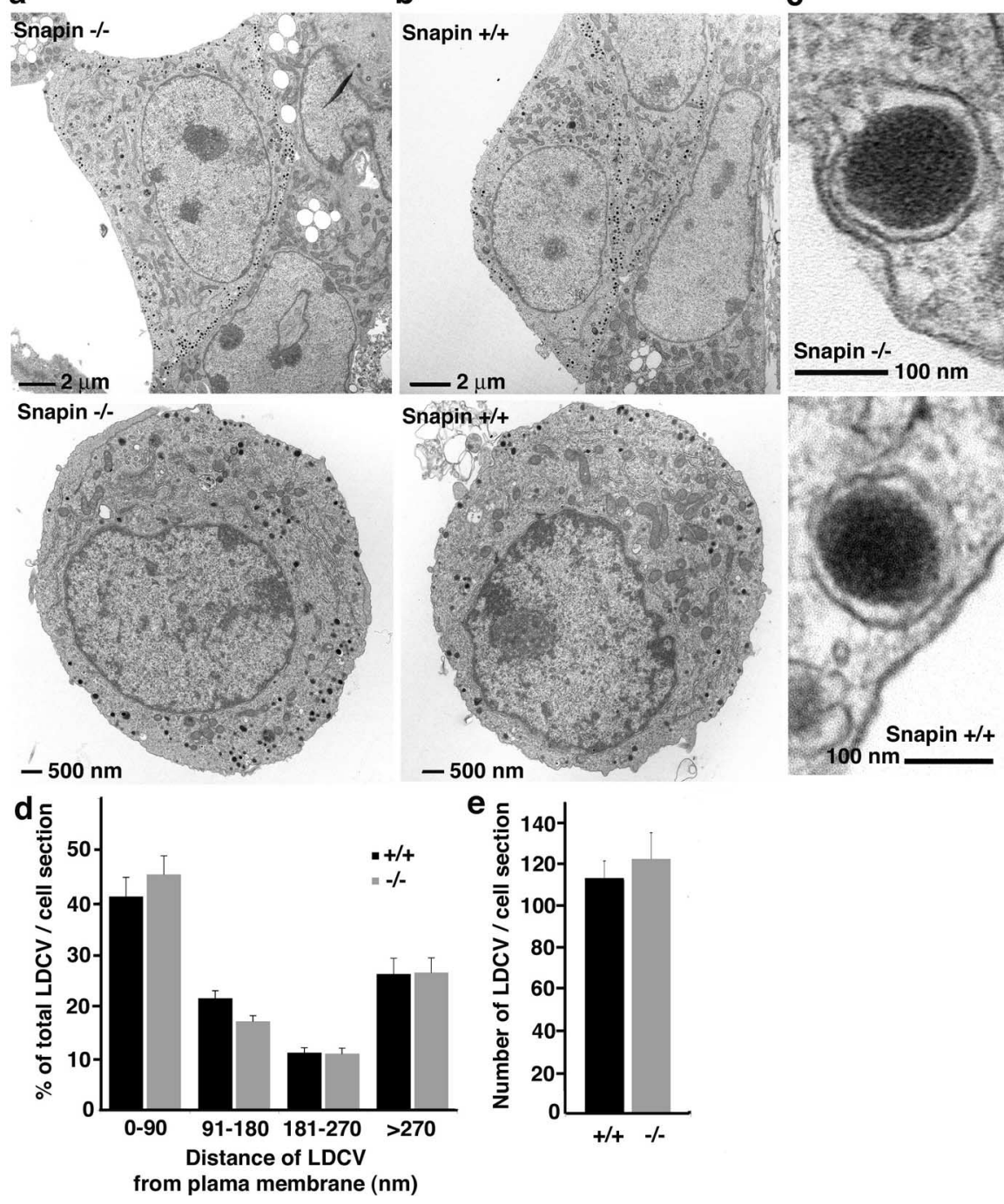

Figure 6. Morphologically normal docking of LDCVs in the absence of Snapin. $A, B$, Electron micrographs of isolated chromaffin cells from snapin $\mathrm{KO}(-/-)(\boldsymbol{A})$ and wild-type $(+/+)(\boldsymbol{B})$ animals. In both cell types, most vesicles were found aligned with the plasma membrane. C, Closeup of a single docked vesicle from both cell types. D, Distribution of vesicles for the distance between the center of chromaffin granules and the plasma membrane in both cell types (16 wild-type cells and $17 \mathrm{KO}$ cells from 4 littermates; mean \pm SEM). Note that there is no defect in morphological docking of the LDCVs $(0-90 \mathrm{~nm}$ between the center of chromaffin granules and the plasma membrane) in the absence of Snapin. $\boldsymbol{E}$, No significant difference in the total number of vesicles per cell section (mean \pm SEM) from both wild-type and $\mathrm{KO}$ cells as indicated. Error bars represent SEM.

fin granules in the absence of Snapin, proving a postdocking function of Snapin; (3) in addition, our calcium ramp experiments showed that neither the $\mathrm{Ca}^{2+}$ sensitivity nor the $\mathrm{Ca}^{2+}$ cooperativity of secretion is changed in the absence of Snapin, excluding the possibility that Snapin is directly involved in the final $\mathrm{Ca}^{2+}$-triggered fusion reaction; (4) exocytosis of LDCVs in snapin mutant chromaffin cells displayed a selective reduction in the exocytotic burst without a change in the sustained component, further excluding the possibility of a general defect in secretory granule biogenesis; and (5) Snapin is relatively enriched in immunoisolated LDCVs and is associated with the vesicle membrane protein synaptotagmin-1. Altogether, our results of biochemical, morphological, and electrophysiological studies using snapin knock-out mice support our conclusion that Snapin plays a role in modulating neurosecretion, likely by stabilizing the release-ready vesicles.

Chromaffin cells are derived embryonically from the neural crest and secrete catecholamines through the fusion of LDCVs with the plasma membrane by the same conserved fusion machinery that functions in neurons (Morgan and Burgoyne, 1997; Rettig and Neher, 2002). Our electrophysiological studies demonstrated that deletion of snapin leads to a specific reduction in burst exocytosis from adrenal chromaffin cells, which can be fully rescued by overexpressing wild-type Snapin in mutant cells. The complete recovery of the exocytotic burst size suggested that Snapin is responsible for the observed reduction. The exocytotic burst in chromaffin cells represents the $\mathrm{Ca}^{2+}$-dependent release of primed vesicles from two different pools, slowly releasable pool (SRP) and rapidly releasable pool (RRP), whereas the slower phase of secretion (the sustained component) represents vesicles that were unprimed at the onset of stimulation and that are mobilized in a use-dependent manner (Rettig and Neher, 2002; Sorensen, 2004). Although release from both SRP and RRP is dependent on preassembled SNARE complexes, $\mathrm{Ca}^{2+}$ dependent fusion occurs with a 10 times slower rate constant from the SRP (three vesicles per second) than from the RRP (30 vesicles per second). The most likely explanation for the different rate constants lies in the association of different $\mathrm{Ca}^{2+}$ sensors with the SNARE complex. Secretion in synaptotagmin-1 knock-out chromaffin cells consists of only the SRP, arguing for synaptotagmin- 1 as the $\mathrm{Ca}^{2+}$ sensor for release from the RRP (Voets et al., 2001a). The identity of the $\mathrm{Ca}^{2+}$ sensor for the SRP has not been resolved; however, it seems likely that one of the many isoforms of synaptotagmin serves this purpose. Exocytosis of LDCVs in snapin mutant chromaffin cells displayed a selective reduction in the exocytotic burst without a change in the sustained component, suggesting a decrease in pool size of the release-ready vesicles that is mediated through an effect on priming-unpriming reactions. Because deletion of snapin expression affects the burst but not the sustained component, it is likely acting through a reduction in the backward rate constant $\left(k_{-1}\right.$; unpriming reaction) instead of enhancing the forward rate constant $\left(k_{1}\right.$; priming reaction) to maintain the size of the readily releasable pool. Based on our combined biochemical and electrophysiological observations, we propose that Snapin stabilizes the release-ready vesicles by enhancing the interaction of the SNARE complexes with synaptotagmin-1 or other isoforms during the vesicle maturation/priming process, a critical step in the structural and functional coupling of the $\mathrm{Ca}^{2+}$ sensors with the SNARE-based fusion machinery (Fig. 7). This assumption is supported by our biochemical observations that deletion of Snapin leads to a marked reduction in the amount of synaptotagmin-1-SNARE complex immunoprecipitated by either anti-SNAP-25 or anti- 
synaptotagmin-1 antibodies. Furthermore, this assumption is also consistent with our previous findings that recombinant Snapin enhances the interaction of synaptotagmin-1 and SNAP-25 in vitro (Ilardi et al., 1999; Chheda et al., 2001).

In addition to binding to SNAP-25, Snapin forms a complex with SNAP-23 (Buxton et al., 2003; Ruder et al., 2005) and modulates PKA-mediated recruitment of transient receptor potential vanilloid subtype 1 channels to the plasma membrane in dorsal root ganglion neurons via synaptotagmin IX and SNAREdependent exocytosis (Morenilla-Palao et al., 2004). Snapin was also copurified with biogenesis of lysosome-related organelles complex-1, suggesting its potential role in the endocytic pathway (Starcevic and Dell'Angelica, 2004). Thus, Snapin, as many other SNARE regulatory proteins (Mullock et al., 1998; Martinez et al., 2000; Chen and Scheller, 2001; Jaiswal et al., 2002; Feldmann et al., 2003; Rao et al., 2004), likely plays a general modulatory role in SNARE-mediated membrane fusion events in addition to its participation in $\mathrm{Ca}^{2+}$-regulated neurosecretion.

A recent report showed that $<1 \%$ of SNAP-25 in brain homogenates bound to GST-Snapin in the in vitro pull-down experiments and that overexpression of the Snapin C-terminal peptide in cultured hippocampal neurons failed to influence synaptic transmission (Vites et al., 2004), arguing against the proposed role of Snapin in vesicle exocytosis. However, Snapin is expressed at a relatively low level ( $\sim 1 \%$ of SNAP-25 in neurons) (Vites et al., 2004) and is proposed to act as a modulator for vesicle priming rather than an essential component of the basic fusion machinery. Thus, one would not expect a high affinity and stoichiometric interaction between Snapin and its binding targets in vitro. We repeated the pull-down assays under the same in vitro conditions as reported previously (Vites et al., 2004), and our results showed that $\sim 2 \%$ of SNAP- 25 from brain homogenates was pulled down by GST-Snapin. As a binding control under the same conditions, $5-10 \%$ of SNAP-25 was pulled down by GSTsyntaxin-1A or GST-VAMP2, and 1\% of synaptotagmin-1 was bound to GST-syntaxin-1A, the well-characterized and stabled interactions with physiological relevance of synaptic vesicle exocytosis (supplemental Fig. 2, available at www.jneurosci.org as supplemental material). The relatively low-binding affinity between Snapin and SNAP-25 is comparable with the observed interaction of syntaxin with synaptotagmin under the same biochemical conditions and might also reflect a transient and weak interaction between these proteins in the buffer with detergent. Thus, our biochemical pull-down studies are consistent with recent reports showing the specific interactions of Snapin with both SNAP-25 and SNAP-23 (Buxton et al., 2003; Ruder et al., 2005). Also, overexpression of C-terminal peptides (Vites et al., 2004), which lack the PKA phosphorylation site at Ser-50, would not be an effective way to test the role of Snapin in neurons, because Thakur et al. (2004) reported that only expression of the fulllength Snapin after PKA phosphorylation could influence synaptic vesicle exocytosis in cultured hippocampal neurons. Because overexpression and peptide injection studies yield different results in different systems, our present studies using genetic ma- nipulation of the snapin gene followed by phenotypic analysis is critical in addressing whether Snapin plays a role in neuroexocytosis. Our results demonstrated that the association of synaptotagmin-1 with SNAP-25 in brain homogenates of snapin mutant mice is significantly decreased. Using flash photolysis of caged calcium as a fast stimulus and high-temporal-resolution measurement of membrane capacitance and catecholamine release, we found that deletion of snapin in chromaffin cells led to a $45 \%$ reduction of calcium-dependent burst exocytosis, whereas the sustained release phase remained unaffected. Furthermore, reintroduction of Snapin into the mutant cells could fully rescue this inhibitory effect within hours, indicating the specificity of the observed burst reduction after snapin deletion. Thus, our biochemical and electrophysiological studies of snapin knock-out mice indicate that Snapin indeed plays a modulatory role in neurosecretion.

In conclusion, our present results illustrate a functional contribution of Snapin to the regulation of neuroexocytosis and provide a molecular mechanism of how Snapin modulates vesicle priming. However, a number of key questions remain to be addressed. How does Snapin regulate the interaction of synaptotagmin with the SNARE complex? Does the role of Snapin require other factors at release sites? Does Snapin participate in general intracellular membrane trafficking by promoting interactions of other synaptotagmins with the non-neuronal SNARE complex? Addressing these questions with snapin knock-out mice will contribute to our understanding of how Snapin regulates vesicle priming and, by extension, the molecular and physiological details of how this protein modulates synaptic transmission.

\section{References}

Ashery U, Varoqueaux F, Voets T, Betz A, Thakur P, Koch H, Neher E, Brose N, Rettig J (2000) Munc13-1 acts as a priming factor for large dense-core vesicles in bovine chromaffin cells. EMBO J 19:3586-3596.

Augustine GJ (2001) How does calcium trigger neurotransmitter release? Curr Opin Neurobiol 11:320-326.

Bai J, Wang CT, Richards DA, Jackson MB, Chapman ER (2004) Fusion pore dynamics are regulated by synaptotagmin ${ }^{\star}$ t-SNARE interactions. Neuron 41:929-942. 
Bennett MK, Calakos N, Scheller RH (1992) Syntaxin: a synaptic protein implicated in docking of synaptic vesicles at presynaptic active zones. Science 257:255-259.

Buxton P, Zhang XM, Walsh B, Sriratana A, Schenberg I, Manickam E, Rowe $\mathrm{T}$ (2003) Identification and characterization of Snapin as a ubiquitously expressed SNARE-binding protein that interacts with SNAP23 in nonneuronal cells. Biochem J 375:433-440.

Calakos N, Bennett MK, Peterson K, Scheller RH (1994) Protein-protein interactions contributing to the specificity of intracellular vesicular trafficking. Science 263:1146-1149.

Chapman ER (2002) Synaptotagmin: a $\mathrm{Ca}^{2+}$ sensor that triggers exocytosis? Nat Rev Mol Cell Biol 3:498-508.

Chen YA, Scheller RH (2001) SNARE-mediated membrane fusion. Nat Rev Mol Cell Biol 2:98-106.

Chheda MG, Ashery U, Thakur P, Rettig J, Sheng ZH (2001) Phosphorylation of Snapin by PKA modulates its interaction with the SNARE complex. Nat Cell Biol 3:331-338.

Deng CX, Xu X (2004) Generation and analysis of Brcal conditional knockout mice. Methods Mol Biol 280:185-200.

Fasshauer D, Eliason WK, Brünger AT, Jahn R (1998) Identification of a minimal core of the synaptic SNARE complex sufficient for reversible assembly and disassembly. Biochemistry 37:10354-10362.

Feldmann J, Callebaut I, Raposo G, Certain S, Bacq D, Dumont C, Lambert N, Ouachee-Chardin M, Chedeville G, Tamary H, Minard-Colin V, Vilmer E, Blanche S, Le Deist F, Fischer A, de Saint Basile G (2003) Munc13-4 is essential for cytolytic granules fusion and is mutated in a form of familial hemophagocytic lymphohistiocytosis (FHL3). Cell 115:461-473.

Hilfiker S, Greengard P, Augustine GJ (1999) Coupling calcium to SNAREmediated synaptic vesicle fusion. Nat Neurosci 2:104-106.

Ilardi JM, Mochida S, Sheng ZH (1999) Snapin: a SNARE-associated protein implicated in synaptic transmission. Nat Neurosci 2:119-124.

Jahn R, Sudhof TC (1999) Membrane fusion and exocytosis. Annu Rev Biochem 68:863-911.

Jaiswal JK, Andrews NW, Simon SM (2002) Membrane proximal lysosomes are the major vesicles responsible for calcium-dependent exocytosis in non-secretory cells. J Cell Biol 159:625-635.

Martinez I, Chakrabarti S, Hellevik T, Morehead J, Fowler K, Andrews NW (2000) Synaptotagmin VII regulates $\mathrm{Ca}^{2+}$-dependent exocytosis of lysosomes in fibroblasts. J Cell Biol 148:1141-1149.

Morenilla-Palao C, Planells-Cases R, Garcia-Sanz N, Ferrer-Montiel A (2004) Regulated exocytosis contributes to protein kinase $\mathrm{C}$ potentiation of vanilloid receptor activity. J Biol Chem 279:25665-25672.

Morgan A, Burgoyne RD (1997) Common mechanisms for regulated exocytosis in the chromaffin cell and the synapse. Semin Cell Dev Biol 8:141-149.

Mullock BM, Bright NA, Fearon CW, Gray SR, Luzio JP (1998) Fusion of lysosomes with late endosomes produces a hybrid organelle of intermediate density and is NSF dependent. J Cell Biol 140:591-601.

Oyler GA, Higgins GA, Hart RA, Battenberg E, Billingsley M, Bloom FE, Wilson MC (1989) The identification of a novel synaptosomalassociated protein SNAP-25 differentially expressed by neuronal subpopulations. J Cell Biol 109:3039-3052.
Rettig J, Neher E (2002) Emerging roles of presynaptic proteins in $\mathrm{Ca}^{2+}$ triggered exocytosis. Science 298:781-785.

Rao SK, Huynh C, Proux-Gillardeaux V, Galli T, Andrews NW (2004) Identification of SNAREs involved in synaptotagmin VII-regulated lysosomal exocytosis. J Biol Chem 279:20471-20479.

Ruder C, Reimer T, Delgado-Martinez I, Hermosilla R, Engelsberg A, Nehring R, Dorken B, Rehm A (2005) EBAG9 adds a new layer of control on large dense-core vesicle exocytosis via interaction with Snapin. Mol Biol Cell 16:1245-1257.

Söllner T, Whiteheart SW, Brunner M, Erdjument-Bromage H, Geromanos S, Tempst P, Rothman JE (1993) SNAP receptors implicated in vesicle targeting and fusion. Nature 362:318 -324.

Sorensen JB (2004) Formation, stabilisation and fusion of the readily releasable pool of secretory vesicles. Pflügers Arch 448:347-362.

Sorensen JB, Matti U, Wei SH, Nehring RB, Voets T, Ashery U, Binz T, Neher E, Rettig J (2002) The SNARE protein SNAP-25 is linked to fast calcium triggering of exocytosis. Proc Natl Acad Sci USA 99:1627-1632.

Sorensen JB, Nagy G, Varoqueaux F, Nehring RB, Brose N, Wilson MC, Neher E (2003) Differential control of the releasable vesicle pools by SNAP-25 splice variants and SNAP-23. Cell 114:75-86.

Speidel D, Bruederle CE, Enk C, Voets T, Varoqueaux F, Reim K, Becherer U, Fornai F, Ruggieri S, Holighaus Y, Weihe E, Bruns D, Brose N, Rettig J (2005) CAPS1 regulates catecholamine loading of large dense-core vesicles. Neuron 46:75-88.

Starcevic M, Dell'Angelica EC (2004) Identification of snapin and three novel proteins (BLOS1, BLOS2, and BLOS3/reduced pigmentation) as subunits of biogenesis of lysosome-related organelles complex-1 (BLOC1). J Biol Chem 279:28393-28401.

Thakur P, Stevens DR, Sheng ZH, Rettig J (2004) Effects of PKA-mediated phosphorylation of Snapin on synaptic transmission in cultured hippocampal neurons. J Neurosci 24:6476-6481.

Trimble WS, Cowan DM, Scheller RH (1988) VAMP-1: a synaptic vesicleassociated integral membrane protein. Proc Natl Acad Sci USA 85:4538-4542.

Tucker WC, Edwardson JM, Bai J, Kim HJ, Martin TF, Chapman ER (2003) Identification of synaptotagmin effectors via acute inhibition of secretion from cracked PC12 cells. J Cell Biol 162:199-209.

Vites O, Rhee JS, Schwarz M, Rosenmund C, Jahn R (2004) Reinvestigation of the role of snapin in neurotransmitter release. J Biol Chem 279:26251-26256.

Voets T, Moser T, Lund PE, Chow RH, Geppert M, Sudhof TC, Neher E (2001a) Intracellular calcium dependence of large dense-core vesicle exocytosis in the absence of synaptotagmin I. Proc Natl Acad Sci USA 98:11680-11685.

Voets T, Toonen RF, Brian EC, de Wit H, Moser T, Rettig J, Sudhof TC, Neher E, Verhage M (2001b) Munc18-1 promotes large dense-core vesicle docking. Neuron 31:581-591.

Yoshida A, Oho C, Omori A, Kuwahara R, Ito T, Takahashi M (1992) HPC-1 is associated with synaptotagmin and conotoxin receptor. J Biol Chem 267:24925-24928.

Zhang X, Kim-Miller MJ, Fukuda M, Kowalchyk JA, Martin TF (2002) $\mathrm{Ca}^{2+}$-dependent synaptotagmin binding to SNAP-25 is essential for $\mathrm{Ca}^{2+}$-triggered exocytosis. Neuron 34:599-611. 